\title{
Microvascular disease in chronic thromboembolic pulmonary hypertension: the story continues
}

\author{
William R. Auger and Nick H. Kim \\ Affiliation: Pulmonary and Critical Care Medicine, University of California San Diego, La Jolla, CA, USA.
}

Correspondence: William R. Auger, UCSD Healthcare, Pulmonary and Critical Care Medicine, 9300 Campus Point Drive, La Jolla, CA 92037, USA. E-mail: baugerAUCSD.edu

○

@ERSpublications

Research uncovers post-capillary microvascular changes in CTEPH and new insight into pathophysiology of disease http://ow.ly/AWk9j

In their 1993 report, MOSER AND BLOOR [1] described an array of microvascular "pulmonary hypertensive" lesions in patients with operable chronic thromboembolic disease. Although it was concluded that these findings in any one patient did not "preclude a positive haemodynamic and clinical result", these early observations became the foundation of our current understanding of the evolution of pulmonary hypertension and right heart failure, following the establishment of proximal vessel, occlusive organised thromboembolic disease [2,3]. Despite the significance and role of the microcirculation in chronic thromboembolic pulmonary hypertension $(\mathrm{CTEPH})$, our understanding of the histopathology remains rather rudimentary [4] and previously confined to descriptions of the precapillary pulmonary circulation $[5,6]$. Accordingly, the report from Dorfmüller et al. [7] in the current journal is a timely re-examination of this subject. In their report, the authors included analysis of the native lungs from 16 select patients with CTEPH receiving lung transplantation and in one case through an autopsy. This combined series consisted both of CTEPH cases deemed inoperable $(n=8)$ and CTEPH patients with residual pulmonary hypertension after pulmonary endarterectomy (PEA) $(n=9)$. In addition to previously reported defects seen in the pulmonary arteries, they discovered abnormalities in the capillary bed (similar to defects seen in pulmonary capillary haemangiomatosis) as well as the post-capillary circulation with involvement of the pulmonary veins. The observed degree of venous fibrosis/remodelling and haemangiomatosis-like foci was reported to be of moderate intensity and less pronounced than those seen in pulmonary veno-occlusive disease. Nevertheless, this represents a unique histopathologic description of capillary and post-capillary defects in CTEPH, and widens our awareness of the spectrum of microvascular defects in this form of pulmonary hypertension.

The clinical significance of this report, however, is unclear and the authors were prudent to conclude that these observations required further investigation. It is widely regarded that PEA is the optimal treatment for patients with $(\mathrm{CTEPH})[8,9]$. This surgical procedure involves the removal of chronic organised thrombi obstructing the proximal pulmonary vessels; and does not address the potential concomitant microvascular disease present beyond the reach of even the most experienced PEA surgeon. And in the majority of patients that experience a favourable pulmonary haemodynamic outcome, especially in those patients with severe pulmonary hypertension pre-operatively, are there not similar microvascular changes observed in these cases? If so, is it simply a matter of the degree of microvascular involvement that separates those patients who do well with surgery and those who do not? And as mentioned by the authors, what imaging or diagnostic tools might be developed that will quantitate the involvement of the microvascular disease in vivo to better exclude those patients unlikely to benefit from an endarterectomy. Do these adaptive vascular

Received: Aug 252014 | Accepted: Aug 262014

Conflict of interest: Disclosures can be found alongside the online version of this article at erj.ersjournals.com

Copyright @ERS 2014 
changes "de-model" after a successful endarterectomy with the relief of the post-obstructive pressure gradient; as we know happens with the bronchial systemic vessels [10]? And are some of these microvascular findings, particularly the observation of post-capillary venous remodelling and bronchial to pulmonary venous shunting, important to the development of reperfusion lung injury and pulmonary haemorrhage following endarterectomy? As was the case following the initial descriptions of small vessel pathology in CTEPH, the report from DORFMÜLLER et al. [7] raises yet more questions than it seems to answer, which of course is the hallmark of all important observations.

\section{References}

1 Moser KM, Bloor CM. Pulmonary vascular lesions occurring in patients with chronic major vessel thromboembolic pulmonary hypertension. Chest 1993; 103: 685-692.

2 Lang IM, Pesavento R, Bonderman D, et al. Risk factors and basic mechanisms of chronic thromboembolic pulmonary hypertension: a current understanding. Eur Respir J 2013; 41: 462-468.

3 Delcroix M, Vonk Noordegraaf A, Fadel E, et al. Vascular and right ventricular remodelling in chronic thromboembolic pulmonary hypertension. Eur Respir J 2013; 41: 224-32.

4 Tuder RM, Archer SL, Dorfmüller P, et al. Relevant issues in the pathology and pathobiology of pulmonary hypertension. J Am Coll Cardiol 2013; 62: D4-D12.

5 Yi ES, Kim H, Ahn H, et al. Distribution of obstructive intimal lesions and their cellular phenotypes in chronic pulmonary hypertension: a morphometric and immunohistochemical study. Am J Respir Crit Care Med 2000; 162: 1577-1586.

6 Galiè N, Kim NH. Pulmonary microvascular disease in chronic thromboembolic pulmonary hypertension. Pro Am Thorac Soc 2006; 3: 571-576.

7 Dorfmüller $\mathrm{P}$, Günther S, Ghigna MR, et al. Microvascular disease in chronic thromboembolic pulmonary hypertension: a role for pulmonary veins and systemic vasculature. Eur Respir J 2014; 44: 1275-1288.

8 Madani MM, Auger WR, Pretorius V, et al. Pulmonary endarterectomy: recent changes in a single institution's experience of more than 2,700 patients. Ann Thorac Surg 2012; 94: 97-103.

9 Jenkins DP, Madani M, Mayer E, et al. Surgical treatment of chronic thromboembolic pulmonary hypertension. Eur Respir J 2013; 41: 735-742.

10 Fadel E, Wijtenburg E, Michel R, et al. Regression of the systemic vasculature to the lung after removal of pulmonary artery obstruction. Am J Respir Crit Care Med 2006; 173: 345-349. 